\title{
Método científico e controvérsias nas Geociências
}

\author{
José Roberto Serra Martins \\ Doutorando no Programa de Pós-Graduação em Ensino e História \\ de Ciências da Terra, IG-Unicamp. Docente do Instituto Federal de \\ Educação, Ciência e Tecnologia de São Paulo, São João da Boa Vista, SP. \\ serra@ifsp.edu.br \\ Celso Dal Ré Carneiro \\ Instituto de Geociências, UniversidadeEstadual de Campinas, \\ Campinas, SP. \\ cedrec@ige.unicamp.br
}

\begin{abstract}
The SCIENTIFiC Method And Controversies in GeOsciences. This article is a first step of a walk towards building a proposal for a Geosciences curriculum in higher education. The discussion starts from the fact that controversies are fundamental to any science, and the debate is essential for questioning the principles and improving a conceptual training process. This article aims to demonstrate that the fluidity of today's world exerts an effective action over science, helping to break down the metanarratives and to reveal essentialisms. A subdivision of the history of Geosciences into periods is also presented, as a limited tool to reach understanding. This paper proposes that every scientist should assume a social function distinct from the current one, bringing to the center of the debate the voices of people situated at the margins of knowledge, while he/she can democratize in society the results of his/her experiences. This may enable the common citizen to agency his/her own demands, based on this knowledge.Citation: Martins J.R.S., Carneiro C.D.R. 2014. Método científico e controvérsias nas Geociências. Terræ Didatica, 10(3):240-249. http://www.ige.unicamp.br/terraedidatica/.
\end{abstract}

KEYWORDS: Controversies in Geosciences; Post-Colonialism; scientific method.

RESUMO Este artigo representa o primeiro passo de uma caminhada na direção de proposta original de um currículo de ensino superior em Geociências. Partindo do fato que as polêmicas são basilares a qualquer ciência, sendo o debate fundamental ao questionamento dos princípios e ao processo de formação conceitual, e que as periodizações históricas das Geociências constituem instrumentos de alcance limitado à sua compreensão, este artigo visa demonstrar como a fluidez está a atuar sobre as ciências, ajudando a derrubar metanarrativas e desvelar essencialismos. Este trabalho propõe que todo cientista deva: (a) assumir função social diversa da atual, ao trazer, para o centro do debate, vozes dos que estão à margem do saber; (b) democratizar os resultados de suas experiências junto à sociedade, possibilitando ao cidadão comum agenciar suas próprias demandas, tomando por base este conhecimento.

PALAVRAS-CHAVES: Controvérsias em Geociências; Pós-Colonialismo; método científico. 


\section{Introdução}

"O homem da era tecnológica, (...), dono de imenso poder sobre a natureza, tem tanto saber e tão pouca sabedoria! Sabe tanto como fazer, mas não para que e o porquê...”.

Maria Lúcia de Arruda Aranha (1992)

"Numa linguagem mais em voga, diríamos que a técnica nos dá o como fazer enquanto a ciência procura nos oferecer o porquê".

Régis de Morais (1988)

Nos dias atuais, vê-se crescer o acirramento dos debates entre representantes das Ciências e de um movimento que poderíamos chamar, grosso modo, de sociologia (ou antropologia) das ciências ("social studies in science"). O debate, marcado pela segregação entre ciências e humanidades, originou-se da radicalização das posições antagônicas assumidas por ambos os grupos:

- Os cientistas por julgarem que apenas a ciência pode levar ao progresso; por tenderem a crer na neutralidade da ciência, afirmando que as decisões tomadas em nome desta não são permeadas por juízos de natureza, moral ou política; eles são, todavia, criticados por "repetirem" apenas o que aprenderam a fazer, ou seja, a agirem sem (ou com pouca) autonomia;

- Os sociólogos - ou antropólogos - por não acreditarem na existência de uma ciência desvinculada de demandas sociais, sendo tal distanciamento o principal motivo das controvérsias entre ciências e humanidades e da crise vivida por essas (Sousa Santos 2003); eles são, entretanto, criticados por serem reconhecidos profissionalmente como cientistas sociais, por utilizarem dados estatísticos para comprovar seus pontos de vista e/ou buscarem um paradigma (ou invariante) que pudesse explicar o mundo em que vivemos.

Entretanto, é notório que muitos dos avanços científicos surgiram de disputas - e controvérsias entre: (i) membros filiados a uma mesma disciplina, mas com pontos de vista opostos, (Monteiro 2007); (ii) indivíduos pertencentes a comunidades científicas diversas (Stengers 2002); (iii) cientistas e filósofos da ciência (Borrón 1988, Rudwick 1987). As referências aqui citadas funcionarão como alicerces à argumentação que será apresentada neste ensaio.
Nas Geociências são muitos os exemplos de controvérsias que culminaram na formulação de princípios, teorias e modelos denominados científicos. A tese Controvérsias geológicas: seu valor científico-histórico e didático (Monteiro 2007) mostra que muitos pontos considerados obscuros da teoria geológica (Tempo Geológico; Deriva Continental ou Teoria da Tectônica de Placas; Extinções de espécies em massa) não só ajudaram a estabelecer os princípios e os modelos atuais como contribuíram para sua divulgação, esclarecendo-os por meio de debates e pelo aumento da produção científica, devido ao crescimento do número de pesquisadores envolvidos na busca por soluções.

Stengers defende, na obra $A$ invenção das ciências modernas, a possibilidade de utilizar o registro político em defesa das ciências. Entretanto, afirma a impossibilidade de se compreender a atividade individual do cientista sem que se leve em consideração a tradição histórica na qual se enraíza seu compromisso e, talvez, sua singularidade, a qual se baseia na distinção sujeito/objeto, sugerindo uma possível segregação entre poder e ciência (Stengers 2002, p. 29, 50 e 160).

Borrón, por seu turno, mostra na obra A filosofia e as ciências: métodos e processos (1988, p.23-45) que a segregação entre filosofia e ciências, decorrente da ontologia do método científico e do posicionamento dos filósofos, foi prejudicial à análise destes quanto à ciência, gerando uma série de ataques dos cientistas à metafísica, tomando-a por elucubrações sem propósito.

Por fim, Rudwick critica no prólogo do livro El significado de los fósiles, a posição dos cientistas Adams e Geikie: O primeiro, por tratar a história da Geologia, na obra The birth and development of the Geological Sciences (1954), como "fábulas que pudessem ser lidas por todos que, dotados de senso de humor e em momentos de ócio, quisessem uma atividade mental recreativa" (Rudwick 1987, p.16); o segundo, por tratar, na obra Founders of Geology (1962), a Geologia como ciência de uns poucos que batalharam para "libertá-la do obscurantismo", estando estes divididos em dois grupos: o dos que lutaram "pelo certo" e o dos que pelejaram "pelo errado" (Rudwick 1987, p.17).

Este artigo, que se pretende o primeiro de uma série, constituirá o passo inicial de uma caminhada na direção de uma proposta curricular de viés póscolonialista ao ensino superior em Geociências. Entre suas metas estão:

1. Mostrar que as polêmicas são basilares a qualquer ciência, sendo o debate funda- 
mental ao questionamento dos princípios, ao processo de formação conceitual e, quando possível, à aceitação de que todo conceito, lei ou teoria é historicamente determinado, podendo mesmo ser descartado(a) pela mudança paradigmática;

2. Analisar as Geociências a partir de um enfoque científico-histórico, tal como sugerido por Monteiro (2007), que, em princípio, poderia servir à edificação de uma periodização, para, a seguir, desconstruí-la, sempre associando os caminhos trilhados pelas ciências e as características do trabalho do sociólogo, tal como preconizado por Bourdieu, Chamboredon e Passeron (2002).

3. Mostrar, ao final da análise, como a fluidez do mundo atual (Bauman 2005) está a atuar sobre as ciências, sobre a construção dos conceitos científicos e metodologias de ensino de ciências.

\section{Ciências da Terra: fundamentos à análise}

A Geologia, segundo Potapova (2008), tem por objeto de estudo o processo histórico-geológico, estudando os processos naturais que ocorrem no domínio do planeta Terra ao longo do tempo. Ela procura, por meio dos objetos de investigação (a própria crosta terrestre, afloramentos, rochas, estratos etc.), analisar traços, marcas e/ou vestígios deixados por estes processos, interpretando-os e compreendendo-os de modo sincrônico e anacrônico, possibilitando uma análise dialética das Ciências da Terra ou Geociências.

Adotando enfoque sistêmico, as Geociências estabelecem princípios e congregam saberes que visam explicar as transformações da matéria e a evolução geológica, geográfica, geodésica e geofísica do planeta Terra, bem como sobre os movimentos ocorridos na matéria. Assim como outras ciências históricas, as Geociências distinguem-se pela interpretação dos fatos (geológicos) em sua explicação, tal como defendido pela hermenêutica (Frodeman 1995). O pensamento geológico é típico "representante do caráter histórico do conhecimento" (Frodeman 1995). Em uma ciência histórica, como a Geologia, a meta não é identificar leis nomotéticas e descobrir características universais, mas estabelecer uma possível ordem e extensão cronológica dos fatos geológicos locais, regionais ou globais. Carneiro e Gonçalves (2013) assinalam ser absolutamente essencial a concepção de processo histórico-geológico definida por Potapova (2008), na medida em que "indica as tendências de desenvolvimento futuro do planeta e contém informes que enriquecem as ciências que estudam o presente".

Deve-se ter em mente que as Geociências: (1) buscam explicar certos tipos de fenômeno, mas podem tornar-se inatingíveis se a ciência for retirada do contexto dos cientistas, na condição de sujeitos; (2) constituem uma ciência histórica, cujo entendimento está ligado ao contexto histórico e sua evolução no tempo. Em concordância com a visão de Monteiro (2007, p. 21), afirma-se que é na "História da Ciência que nos apercebemos do espirito do cientista".

O cientista, como sujeito do conhecimento, constrói os fundamentos científicos apoiando-se em valores e saberes estabelecido. Devido ao fato de suas conclusões serem imprecisas (ou passíveis de certa imprecisão), abrem-se possibilidades: (1) ao esclarecimento das controvérsias científicas em Geociências, todas de natureza subjetiva, e passíveis de serem analisadas sob um enfoque histórico-epistemológico; além de (2) conceituar o processo de "fazer ciência" por meio da controvérsia científica, na condição de objeto de estudo da história das ciências. Quando a controvérsia não se estabelece nas ciências, o conhecimento assume forma de algo já comprovado, que é reforçado e repetido pelos cientistas como um modo de se manter o status quo. Para Trindade (2007, p.189), ao não ser confrontado com as perspectivas histórica e filosófica do conhecimento, "o estudo [das Geociências, especificamente] continua se apoiando no conceito positivista de que a Ciência é fruto do trabalho de cientistas que descobrem as verdades escritas na natureza", como se a polêmica não tivesse lugar, possibilidade ou utilidade.

No que tange ao estudo da História das Ciências, a abordagem analítica enfoca os conteúdos de maneira compartimentada e fragmentada, praticamente restringindo a integração dos saberes, pois considera seus elementos de modo isolado. A abordagem sistêmica, por sua vez, valoriza a percepção global e as relações existentes entre os saberes. Assim, cabe a nós, atualmente, construir outras possibilidades de conhecimento. Tomando a complexidade do mundo por premissa, deve-se empreender uma viagem ao cerne de cada disciplina, compreender seus modelos e conceitos, e fazer nascer uma educação científica que se dissemine entre as pessoas, de modo a torná-las agenciadoras de suas próprias demandas. 


\section{A filosofia como alicerce a uma periodização em Ciências da Terra}

\section{Primeiro período: Induzindo conceitos}

Se analisássemos a história das ciências da Terra poderíamos sugerir que a primeira grande descoberta relacionada às Geociências seria atribuída ao método e à ideia que Eratóstenes de Cirene [276196 a.C.] utilizou para resolver um dilema. Ele já havia percebido que o Sol a pino (zênite) projetava sua imagem bem no centro de um poço na cidade de Siena (atual Assuã), por ocasião do solstício de verão. Ele também notou que na cidade de Alexandria, localizada a norte de Siena, durante o solstício de verão, o resultado era diverso do anterior. Supondo o Sol como uma fonte extensa de luz, ele percebeu que os resultados só eram cabíveis se nosso planeta fosse um corpo esférico. Mas qual o tamanho dessa esfera?

Partindo da premissa da perfeita esfericidade da Terra e de que ambas as cidades se encontravam no mesmo meridiano terrestre (conceito desconhecido à época, mas concebido por Eratóstenes de modo preciso) o sábio grego mensurou: (1) o ângulo formado pela projeção do Sol a pino (zênite) em Siena durante o solstício de verão, (2) o ângulo de projeção da sombra de um gnômon (parte do relógio solar que possibilita a projeção de sombra), naquele mesmo dia, em Alexandria, e (3) a distância entre as cidades, avaliado em 5.000 stadias (925 quilômetros), pela marcha das caravanas que cruzavam o deserto deslocando-se em velocidade constante e em linha reta entre Siena e Alexandria; ele calculou o tamanho da Terra com boa precisão.

A descoberta de Eratóstenes revelava um método que partia de premissas e axiomas capazes de leva-lo, por indução, a perceber por meio de um caso particular associado a uma linha geométrica de raciocínio que a projeção paralela dos raios solares não era fenômeno exclusivo àqueles dois pontos da Terra. Utilizando seus conceitos matemáticos e geográficos (de forma original) à situação em apreço, Eratóstenes conseguiu obter a resposta desejada.

Mas o que buscava Eratóstenes ao desejar descobrir o tamanho da Terra? Não há registros deixados pelo próprio que respondessem à questão. Ele, provavelmente, comungava com os preceitos de uma dada cosmogonia (conjunto de lendas e teorias sobre as origens do universo de acordo com as religiões, mitologias e ciências ao longo da história).
A busca por esclarecimentos e/ou injunções a respeito de alguma lenda ou teoria pode ter motivado Eratóstenes a buscar evidências que confirmassem suas concepções cosmogônicas. Cabe lembrar que, àquela época, a astronomia gozava de bom prestígio entre egípcios e babilônios, e a cosmologia (ciência que estudava a origem, estrutura e evolução do Universo) se utilizava de conhecimentos matemáticos, que possibilitavam a construção de teorias e modelos próprios à comprovação dos fatos científicos.

A coexistência de ambas foi verificada em um lapso temporal que vai da Antiguidade Clássica à Idade Média (Franco Jr. 1986, Le Goff 1990). O advento do Renascimento científico e cultural, notadamente ocidental (europeu), parece ter abalado a convivência, principalmente pela introdução de instrumentos ópticos de precisão e pelo desenvolvimento de novas ferramentas matemáticas, que tornaram as teorias cosmológicas mais aceitáveis do ponto de vista racional.

O movimento que levou à segregação entre cosmologia e cosmogonia, constituiu, a nosso ver, a primeira grande mudança paradigmática das Geociências. O movimento, descrito por Randles (1994) não apenas transformou a forma de pensar, analisar e conceber o Universo; a partir da segunda década do século XVI, o movimento deslocou a Terra do centro do universo, ressignificando-a.

\section{Segundo Período: Deduzindo leis naturais}

No período compreendido entre 1520 e 1800 , a Geologia (e as demais ciências da Terra) começou a construir bases científicas sobre as quais se apoiaram seus princípios e se estruturaram seus conceitos. As relações Deus-homem foram substituídas pela relação homem-ambiente, o que acarretou a valorização da capacidade do homem em conceber e transformar a realidade. Deste modo, a visão aristotélica de Mundo, que havia sido reinterpretada pelos teólogos medievais, tornando-se a visão predominante do período medieval, foi substancialmente modificada.

Os séculos XVI e XVII foram marcados (1) pela invenção de importantes instrumentos ópticos voltados à pesquisa, como o microscópio Jansen (1590) e o telescópio Lippershey (1608); (2) pela publicação de obras fulcrais sobre História Natural das plantas, escrita por Fuchs em 1542, do homem , por Vesalius, em 1543, e por Harvey, em 1628, dos minerais, por Agricola, em 1546, dos animais 
e dos fósseis por Gesner, respectivamente nos anos de 1558 e 1565; (3) pelo surgimento dos primeiros princípios geológicos, tal como se vê em Steno (1669). Essas obras, além de introduzir novas técnicas, teorias e conceitos sobre botânica, zoologia, anatomia e fisiologia (entre estas, as noções de fluxo e de sistema), também forneceram princípios e elementos de cunho paleontológico, pedológico e geológico.

Nos séculos citados, rompeu-se a confiança nos métodos utilizados na produção do conhecimento, de tal sorte que fé e contemplação acabaram substituídas por duas correntes epistemológicas distintas: o empirismo e o racionalismo, que tiveram, respectivamente, em Bacon [1561-1626] e Descartes [1596-1650] seus principais representantes. Ambas as correntes, utilizando métodos indutivos para obtenção do saber, foram analisadas (e criticadas) por Immanuel Kant [1724-1804], cuja proposta marcaria a separação entre filosofia e ciências. Para entender a importância deste filósofo, deve-se focalizar, a priori, o contexto científico-filosófico do século XVIII. O século em questão viu surgir um movimento intelectual apoiado pela burguesia: o Iluminismo (ou Ilustração). O movimento, que pregava maior liberdade econômica e política, tornou-se responsável pelas transformações sociais ocorridas ao longo do século XVIII. Entre seus principais representantes estão:

1. John Locke [1632-1704], filósofo realista inglês; introduziu as bases de uma teoria social fundada nos direitos naturais e no contrato social, cuja pedra angular era a liberdade de ir e vir, ou seja, liberdade de trânsito ou fluxo;

2. François Quesnay [1694-1774], médico e economista francês; influenciado pelo método cartesiano, inventou o Tableau Économique, como o qual defende a ideia de existência de fluxo monetário, e cuja gênese se deu pela produção agrícola, força motriz da economia;

3. Adam Smith [1723-1790], economista escocês; defendia a liberdade de mercado e do fluxo de bens e capitais, baseando suas explicações na existência de leis naturais de distribuição de riquezas, sintetizadas no mote: "Deixai fazer, deixai passar, o mundo caminha por si mesmo", que autorregulavam tanto a oferta quanto a demanda de bens e, em consequência, o fluxo destes.

Kant, por seu turno, criticava empiristas devido ao fato de estes alegarem que todo saber vem dos sentidos, e racionalistas, uma vez que estes afirmavam que todos os nossos pensamentos nos são inerentes, próprios. Para Kant, o conhecimento seria formado por juízos universais que antecediam a experiência, os quais derivavam da experiência sensível (Aranha 1992, p.162).

Entretanto, Kant percebeu que as realidades metafísicas não são passíveis de experiências sensíveis, não havendo possibilidade de se afirmar (ou negar) qualquer coisa a respeito da realidade. Kant concluiu pela impossibilidade do conhecimento científico da metafísica. A partir da classificação da razão em especulativa (propícia à ciência) e prática (que orienta a ação humana), Kant demonstrou que a consciência moral, dirigida pelos imperativos categóricos, era responsável por alicerçar os conceitos de autonomia e liberdade, tão caros às críticas (atual e pregressa) das ciências. Gonçalves (2011) cita os estreitos vínculos existentes entre o conhecimento geológico e a Química no fim do século XVIII; mostra que esta ciência representava parcela considerável da base científica que deu origem à moderna Geologia. Afirma existir vínculo intelectual entre Joseph Black [1728-1799] e James Hutton [1726-1797], que estenderemos a Adam Smith, uma vez que há prova documental da amizade destes (Cerqueira 2006, p.669).

A existência de leis naturais, baseadas na existência de processos naturais cíclicos, que possibilitavam o controle dos fluxos não era exclusiva aos fatos econômicos; os fluidos imponderáveis associados à transferência de calor (o calórico) e às reações químicas (o flogisto) representavam paradigmas importantes às ciências físicas e químicas do fim do século XVIII. Exemplarmente, tanto o calórico quanto o flogisto exerceram forte influência na explicação (geológica) da origem de substâncias químicas, como os óxidos, e de alguns tipos de rocha, como o granito.

Por volta de 1780, passou-se a dar maior importância a analise dos processos e não somente ao seu resultado. Por décadas, uma dúvida pairava no ar: Por que a transformação de metais em óxidos conduzia a um aumento da massa do produto, enquanto a mesma reação, para o carvão, implicava na formação de cinzas e redução da massa total? A resposta a este dilema só se tornou possível pela(o): (1) descoberta do oxigênio como constituinte do ar; (2) abandono paulatino dos fluidos imponderáveis, ou seja, do flogisto e do calórico; (3) descoberta da lei de conservação da energia e dos processos de transformação; e (4) desenvolvimento analítico 
sobre a transformação, de um composto em outro, do processo de orogênese ou da evolução do relevo.

\section{Terceiro Período: Da história cíclica à evolutiva por meio do idealismo de Hegel}

O fim do século XVIII e início do século XIX foram marcados por importantes mudanças relativas ao estudo dos minerais, rochas e da Terra (Gonçalves 2011). Nesta época ocorreram o(a): (1) crescimento e generalização da atividade de campo - tal como comprovado pela correspondência, datada de 11 de janeiro de 1829, enviada por Lyell a Murchison; (2) aprofundamento das relações entre Geologia e Mineração - lembrando que, tanto na França, quanto nas regiões que viriam a constituir a Alemanha, não havia separação entre Geologia 'científica' e 'técnica'; (3) ampliação do uso de mapas e representações visuais para o estudo da História Natural - cite-se a elaboração de mapas geológicos por Johann Freiesleben [17741846] sobre a estratigrafia da Turíngia (1815), e o de William Smith [1769-1839], sobre a Geologia da Inglaterra e do País de Gales (1815).

Rudwick (1987, p.159) cita a crítica feita, em 1794, pelo empirista Desmarest [1725-1815] ao racionalista Hutton, "não pelo tamanho da escala temporal que postulava existir, mas pelo fato do caráter cíclico não estar respaldado por observações detalhadas", a qual é corroborada por Hallam (1989, p.25). Deve-se notar que, pelo fato de apresentar caráter evolutivo, a tese de Lamarck foi considerada, em 1802, extremamente especulativa, uma vez que nesta predominava a ideia de que as histórias - a natural incluída - apresentavam caráter cíclico.

Pode-se dizer que a concepção de evolução só passou a ganhar importância nas ciências a partir da análise abalizada sobre o devir realizada pelo filósofo alemão Georg Hegel [1770-1831]. Para este idealista, a ideia de desenvolvimento, evolução, progresso ou devir é fundamental para explicar a realidade em constante mutação, incluindo-se ainda a das ciências. Para Hegel, a natureza é penetrada por tendências. Tudo na natureza tenta tornar-se algo de definido. Todavia, a convergência do processo para seu próprio fim é sempre assintótica. Por esta razão, constata-se que muitas das leis naturais são estatísticas, pois não conseguem descrever, com rígida precisão, "o comportamento de cada ente isolado, mas sim a tendência geral de seu comportamento quando tomado em conjunto" (Borrón 1988, p.138).

Segundo a visão hegeliana, cada conceito conduz ao conceito seguinte por necessidade lógica, ou seja, o conceito desenvolve-se como um organismo passando da potencialidade à realidade, ao fazer brotar novas determinações de si mesmo, que são heterogêneas às apresentadas em seu ponto de partida (Borrón 1988, p.135-136).

A dialética de Hegel é a estrutura contraditória do real; dela advém um novo conceito de história, segundo o qual "o presente é tomado como resultado de um longo e dramático processo, a história não é uma simples acumulação e justaposição de fatos ocorridos no tempo, mas (...) um processo cujo motor interno é a contradição [ou contradição criadora]" (Aranha 1992, p.180. grifo nosso). Daí a importância do texto de Monteiro (2007) e de seu predecessor Hallam (1989).

No caso das Geociências, devemos lembrar que o conceito de evolução é muito caro à compreensão de seu objeto de estudo: o processo histórico-geológico. Até as ciências passarem a se utilizar dos preceitos e da lógica hegelianos, apenas alguns geólogos (como Hutton ou Lyell, por exemplo) parecem convencidos da existência do lento processo de evolução geológica sofrido pelo nosso planeta (Carneiro et al. 1994); processo que ajudou a estabelecer as bases da Teoria do Uniformitarismo (Lyell, 1830), uma das que mais exerceu influência sobre Charles Darwin [1809-1882] ao longo de sua vida.

\section{Quarto Período: Contraposição entre positivismo e materialismo dialético}

Neste período pode-se dizer que houve grande embate entre as perspectivas positivista e materialista nas Geociências: a primeira, por ensejar a transformação da Geologia em ciência por meio da descoberta (ou invenção?) de leis nomotéticas e de princípios universais, totalmente baseados na observação dos fatos, que pudessem explicar o mundo, sua gênese e existência real; a segunda, por querer mostrar que a história geológica da Terra independe da consciência humana, sendo seu movimento propriedade fundamental da matéria, uma vez que os fenômenos são processos em movimento (nada é estático) e "a consciência, ao tomar conhecimento dos determinismos, pode agir sobre o mundo, transformando-o" (Aranha 1992, p.181).

O positivismo de Auguste Comte [1798-1857] influenciou de modo decisivo um grande número de cientistas da segunda metade do século XIX e início do seguinte uma vez que suas metas se apresentavam em maior congruência aos preceitos daquela corrente. Um dos aspectos da ótica positivista afirmava que apenas poderiam ser con- 
sideradas científicas as teses comprovadas por meio de experimentos. Realizavam-se experiências para quase tudo e, por conta disto, alavancaram-se muitos estudos em nome da ciência - alguns dos quais se tornaram polêmicos (Monteiro 2007, p.248).

Tomemos como exemplo a controvérsia que se estabeleceu no meio científico quando as ideias sobre o resfriamento da Terra de William Thomson [1824-1907] - posteriormente, lorde Kelvin - vieram à tona em 1862.

No final da década de 1850, Thomson empenhava-se em resolver o dilema da energia solar, sua origem e fluxos, além dos problemas subsidiários às Ciências da Terra. Ao fazer uma reavaliação do método utilizado por Fourier (sobre a condução de calor) para determinar a história térmica de nosso planeta. Para tal, tomou por base as leis da termodinâmica e por premissa o fato da Terra ter resfriado gradualmente a partir de um estado inicial de fusão.

Utilizando os melhores dados sobre os gradientes geotérmicos e as propriedades físicas das rochas (coletadas até aquele momento), Thomson, partindo da premissa que a temperatura inicial do material fundido era igual a $7000^{\circ} \mathrm{F}$, calculou em 98 milhões de anos o tempo transcorrido desde a solidificação da crosta (ver Carneiro et al. 2005).

Inicialmente, os resultados de Thomson mostravam que as teorias sobre a idade da Terra, propostas até aquele momento, não violavam princípios físicos básicos; a sensação era que os resultados corroboravam a Teoria do Uniformitarismo, apresentada por Lyell em sua obra Princípios de Geologia (1830) e as teses evolutivas, defendidas por Darwin, no livro $A$ origem das espécies (1859). Entretanto, para que os princípios e as teses pudessem ser aceitos, o tempo transcorrido entre a consolidação da crosta e o presente deveria ser de, no mínimo, 300 milhões de anos, o que os inviabilizava.

As demonstrações de Thomson, entretanto, apresentavam considerações físicas que não se mostraram pertinentes após algumas décadas. Por desconhecer o fenômeno da radioatividade, lorde Kelvin não poderia supor a existência de minerais constituídos de elementos que, ao emitir radiação, causavam aquecimento dos corpos rochosos. Este aquecimento levava ao aumento do tempo necessário à consolidação da crosta terrestre.

Entre os fatos que se contrapuseram à demonstração realizada por Thomson, destacam-se as: (1) críticas de John Perry [1850-1920] sobre os parâmetros e o modelo de Terra que foram utilizados; (2) teses de John Joly [1857-1933] autor do livro
Radioatividade em Geologia (1909); (3) investigações sistemáticas das relações $\mathrm{Pb} / \mathrm{U}$ (chumbo-urânio), levadas a termo por Ernest Rutherford [1871-1937] e ultimadas pelo lançamento de $A$ idade da Terra (1931), publicada na série Physics of the Earth.

Como se vê nesta polêmica, físicos e naturalistas (geólogos e biólogos, por exemplo), amiúde, raciocinavam (ou raciocinam?) de modo diferente. Enquanto os primeiros baseavam suas atividades em uma perspectiva dedutiva, ou seja, a partir de ideias individuais faziam emergir uma teoria, os demais se apropriavam de uma perspectiva indutiva, ou seja, a partir de fatos criavam uma teoria abrangente. Mas como raciocinar sob uma perspectiva sociológica?

\section{0 método científico analisado sob uma ótica sociológica}

Clarificando a posição do objeto em relação ao método, e apondo a este suas hipóteses, Bourdieu et al. (2002, p.45) alinham-se ao pensamento de Max Weber [1864-1920] ao afirmar que "é apenas nos campos em que é aplicado um novo método a novos problemas e em que são descobertas, assim, novas perspectivas, que surge também uma nova ciência".

Sociologicamente falando, o método científico não atribui ao objeto apenas um estatuto ontológico, ele define uma atitude mental que afasta a ciência do senso comum. É nessa segregação que a ciência passa a construir o objeto sem abandonar a busca pelos objetos pré-construídos. Pode-se afirmar então que, por mais parcial que seja um objeto de pesquisa, este só pode ser construído em função de uma problemática teórica que "permita submeter a uma interrogação sistemática os aspectos da realidade colocados em relação entre si pela questão que thes é formulada" (Bourdieu et al. 2002, p.48).

Para Bachelard (1973, p.98), o real, por si só, não é capaz de tomar a iniciativa pela formulação de hipóteses. As hipóteses são reveladas quando a teoria se impõe ao método, na intenção de regular um único instrumento, o de interpretar a leitura. Assim, o pesquisador envolvido no estudo social das ciências (social studies in science) deverá estar sempre vigilante à sua missão, percebendo sua submissão a uma construção que perpassa suas ideias e que, na maioria das vezes, ele ignora.

Partindo do pressuposto de que toda prática científica não opera de modo neutro, pode-se considerar que a Ciência associada a pressupostos teóricos, ao 
recusar a formulação de um elenco de hipóteses, condena o cientista a aplicar conjecturas que não diferem de sua ideologia. Contudo, se o sociólogo deseja formatar uma sociologia livre de pressupostos que amarrem suas hipóteses de trabalho, ele deverá, segundo o método científico (defendido pelos positivistas), buscar algo mensurável. Apenas dessa forma a teoria passaria a ser científica, e, filiando-se a um determinado conjunto de paradigmas, acabaria aceita pela comunidade científica.

Não existe, pois neutralidade nas técnicas empregadas na ciência, uma vez que a escolha destas é sempre política e segue a lógica própria do pesquisador, fundamentando-se no paradigma que o cientista defende, as técnicas fazem parte da memória discursiva do mesmo, o que confirma a condição de não-existência da neutralidade. $\mathrm{O}$ que se deve procurar fazer, portanto, é uma ciência pautada por aspectos éticos:

Até mesmo as operações mais elementares e, na prática, as mais automáticas do tratamento da informação implicam escolhas epistemológicas e [de] (...) uma teoria do objeto" (Bourdieu et al. 2002, p.60).

O conhecimento e a construção do objeto de pesquisa advêm da consciência de que todo objeto é consciente e metodicamente construído, sendo que a exploração dos múltiplos aspectos em relação à definição do objeto de estudo, tal como definido por Potapova (2008), deve pressupor um distanciamento decisório em relação aos fatos. Desse modo, toda vez que um sociólogo se interessar pela sociologia das ciências, ele deverá ter em mente que seu objeto de estudo não se constrói no plano factual; da mesma maneira, um físico não deve esperar que a Física se forme apenas por dados do mundo sensível.

A superação desta visão, repleta de essencialismos e que separa o sociólogo do cientista pode, por fim, nos levar à adoção de um viés póscolonialista efluido (Bauman 2005), que aproxime estes profissionais, fazendo-os perceber que a comunhão de saberes é muito mais útil à humanidade do que a - vaidosa - disputa por supremacia intelectual (ou mesmo verbas para a pesquisa).

\section{A fluidez como meta}

Se tomarmos por base as mais recentes teorias a respeito do conhecimento em Geociências, veremos que o entendimento sistêmico do ambiente está a contribuir para formar habilidades cognitivas essenciais à alfabetização científica. Como afirmou Hector Lacreu, por ocasião do II Simpósio de Pesquisa em Ensino e História de Ciências da Terra (2009), "é de suma importância que os conteúdos geológicos sejam ensinados visando à formação política dos cidadãos". É por meio desse processo de ensino (a ser avaliado em próximo artigo), que se mostrará que tal conhecimento torna os cidadãos mais conscientes de seus direitos, levando-os a um agenciamento mais eficiente em relação às suas demandas.

O conceito de agenciamento (Deleuze e Guattari 2007 [1972]) potencializa a conceitualização (construção de um conceito) - e uma prática educacional - que investe no desenvolvimento das capacidades criativas do ser humano. Para estes filósofos, a natureza é fábrica de si mesma e de tudo que dela decorre, não sendo algo dado, mas uma realidade que não pára de produzir a si mesma, também as partes que a compõem (e dela participam) não param de ser produzidas e de participar da produção de si mesmas.

Assim, se a humanidade é parte efetiva da natureza, não há sujeito ou natureza humana natural pronta, nem progresso ou processo de melhoramento, não havendo, em consequência, objetos ideais ou valores universais imutáveis. Como assevera Fuganti (2010) "a natureza humana, seu meio específico e seus objetos estão em processo ininterrupto de modificação e produção de si nos devires, tempos e movimentos reais".

Ao analisar as controvérsias em sua vertente histórico-epistemológica, afirmamos que a história das ciências (ou das Geociências, no caso) revelou um percurso que foi, a um só tempo, inacabado, aberto e subjetivo:

É que a controvérsia, enquanto fenômeno intrínseco à Ciência permitiu a sua consciencialização como realidade e foi aí que se manifestou seu interesse para a construção do conhecimento científico" (Monteiro 2007, p.398).

Se pensarmos no contexto social em que se desenvolve o trabalho científico, analisando a maior parte das condicionantes e - não estritamente - as resultantes de dados empíricos factuais, veremos que todo empreendimento científico é reflexo da vontade, do agenciamento e da razão.

Para Monteiro (2007, p.399), toda controvérsia é dotada de epistemologia própria. A natureza daquilo em que acreditamos, e defendemos até às últimas instâncias, levou-nos a crer em algo que é apenas 
uma hipótese. Entretanto, quando a esta conjectura se juntam provas mais plausíveis e testáveis, a hipótese ganha vigor e, entrementes, pode se tornar um preceito importante para as Geociências, constituindo fundamento basilar à construção de uma teoria científica.

Atualmente, postula-se a existência de uma dívida social das Geociências para com a sociedade. Para Bacci (2009, p.6), a compreensão geológica da natureza, restrita ao espaço dos especialistas, cede lugar, na sociedade, às leituras fragmentárias e não históricas da natureza, o que pode levar à mudança de função do geólogo. Frodeman e Turner (1996), afirmam que, atualmente, em lugar de levantar dados objetivos, voltados à explotação de um dado recurso, por exemplo, os geólogos estão sendo solicitados a avaliar, cada vez mais, os problemas associados aos processos geológicos e aos valores conflitantes de natureza científica, política, econômica e estética em relação a estes.

Como se sabe, o funcionamento do meio físico em uma perspectiva de evolução dinâmica (e histórica) da natureza, tendo por fundamento a abordagem interdisciplinar, desperta nos estudantes - futuros cidadãos - atenção ao significado de muitas atividades humanas, principalmente as que visam à utilização racional dos recursos minerais ou ao uso e ocupação do meio físico, por exemplo.

Este conjunto de saberes é essencial para promover uma nova relação do ser humano com a Natureza, contribuindo na formação de cidadãos críticos e responsáveis com relação à ocupação do planeta e utilização de seus diversos recursos. Além disso,

cria meios para diminuir o impacto ambiental das atividades econômicas, e também busca soluções para os problemas já existentes de degradação do meio ambiente" (Bacci 2009, p.8).

Frodeman (2001), por seu turno, afirma que as Geociências foram, por muito tempo, ignoradas pelas humanidades, sendo tratadas como uma simples fonte de matéria prima para o desenvolvimento industrial. O mesmo autor, contudo, assevera que este tipo de perspectiva está a se transformar, de tal sorte que as Geociências estão a passar da periferia para o centro da conscientização e do debate públicos; para tal, tornar-se-á necessária uma maior conscientização e envolvimento dos cidadãos, em relação aos aspectos políticos e humanistas, na investigação em Geociências.
Em concordância com Bauman, cremos que os sólidos princípios que pareciam vincular um sujeito a uma dada comunidade (científica ou social) estão, aos poucos, se liquefazendo. Estruturas e instituições, muitas das quais glorificavam a ideia de progresso por meio da ciência, tornaram-se fluidas. Nas palavras de Bauman (2005, p.58), não se pode esperar "que a sociedade seja um árbitro das tentativas e erros dos seres humanos (...) de quem se espera (...) [justiça e princípios]". Assim, não havendo quem arbitre as diferenças, estas passam a mostrar uma dimensão que se ocultava sob o manto de consensos inventados.

\section{Considerações finais}

Para mudar o modo instrumental de utilização das práticas de responsabilidade nas Geociências, é preciso que as práticas de relações públicas (ou pedagógicas) negociem performaticamente - nos conflitos locais, cotidianos, particulares - com as comunidades. Concordando com Bhabha afirma-se que a casualidade social não pode ser compreendida adequadamente como um efeito determinado a priori, não podendo a racionalidade das escolhas estar proporcionalmente dividida entre as esferas do privado e do público.

Desse modo, faz-se necessário que todo cientista mude de lugar na sociedade, para não perder sua função pedagógica; passaria a assumir outro papel social, por meio de agenciamentos realizados frente a outros cidadãos, como outros cientistas, seus próprios alunos ou mesmo uma comissão de moradores na busca do atendimento de suas demandas.

Nessa medida, ao compreender as necessidades, desejos e embates cotidianos existentes na sociedade (ou ainda na escola ou na comunidade científica a que pertence), o cientista poderá, por meio de uma decisão autônoma, decidir quais as ações são mais pertinentes para atender aos interesses e escolhas da população.

As ações citadas devem ser levadas a termo por sujeitos que não se comportem como 'dignos representantes comunitários', tais como vereadores, prefeitos, figuras de proa, profissionais ou acadêmicos atuando sozinhos, mas como cidadãos críticos, cujo conhecimento coletivo pressuponha visões específicas da vida pública, da comunidade e do compromisso moral. As ciências, assim como a educação, em geral, e o currículo escolar, em particular, não 
podem ser demandas individuais; é importante que o coletivo esteja e se sinta representado na definição de suas metas e de seus prazos de aplicação, bem como no controle das políticas públicas e avaliação do processo e do resultado final.

\section{Referências bibliográficas}

Adams F.D. 1954. The birth and development of the geological sciences. New York: Dover Publ. 506p.

Aranha M.L.A.1992. História da Educação. São Paulo: Moderna, 288p.

Bacci D.L.C. 2009. A contribuição do conhecimento geológico para a educação ambiental. Pesquisa em debate, v.6, n.2, pp.1-23, jul-dez. 2009.

Bachelard G. 1973. Epistemologia. Barcelona: Anagrama. $254 \mathrm{p}$.

Bauman Z. 2005. Identidade. Trad. Carlos Alberto Medeiros. Rio de Janeiro: Jorge Zahar. 112p.

Bhabha H.K. 2001. O local da cultura. Trad. Myriam de Ávila, Eliana L. L. Reis, Gláucia R. Gonçalves. Belo Horizonte: Ed. UFMG, 395p.

Borrón J.C.G. 1988. A filosofía e as ciências: métodos e processos. Lisboa: Teorema. 198p.

Bourdieu P., Chamboredon J.-C., Passeron J.-C. 2002. A profissão do sociólogo. Trad. Guilherme J. F. Teixeira. 3 ed. Petrópolis: Vozes. 328p.

Carneiro C.D.R., Brito-Neves B.B.de, Amaral I.A.do, Bistrichi C.A. 1994. O Atualismo como princípio metodológico em Tectônica. Bol. Geoc. Petrobrás, 8(2/4):275-293.

Carneiro C.D.R., Gonçalves P.W. 2013. Ciência do Sistema Terra em cursos superiores de formação de geógrafos. In: Vitte A.C. org. 2013. Ensaios sobre Geografia. Campinas: Bertrand Brasil. (cap. submetido em 28.02.2013).

Carneiro C.D.R., Mizusaki A.M.P., Almeida F.F.M.de. 2005. A determinação da idade das rochas. Terrae Didatica, 1(1):6-35. URL: http://www.ige.unicamp.br/terraedidatica/v1/v1_a2.html. Acesso 02.08.2013.

Cerqueira H.E.A.G. 2006. A mão invisível de Júpiter e o método newtoniano de Smith. Estud. Econ. São Paulo, 36(4):667-697.

Deleuze G., Guattari F. 2007 [1972]. Mil Platôs: Capitalismo e Esquizofrenia. v.2. Trad. Ana L. Oliveira e Lúcia C. Leão. Lisboa: Ed. 34. 112p.
Espinosa B. 1978. Ética. São Paulo: Abril Cult.. 294p. (Col. Os Pensadores)

Franco Jr. H. 1986. A Idade Média: o nascimento do ocidente. São Paulo: Ed. Brasiliense. 204p.

Frodeman R. 1995. Geological reasoning: Geology as an interpretative and historical Science.Geol. Soc. Am. Bull., 107(8):960-968.

Frodeman R. 2001. A epistemologia das Geociências. In: L. Marques, J. Praia. coords. 2001. Geociências nos currículos básico e secundário. Aveiro: Univ. Aveiro. p.39-57.

Frodeman R., Turner C. 1996. Geology in a post-industrial society. J. Geosc. Educ.,44:36-37.

Fuganti L. 2010. Agenciamento.URL: http://escolanomade.org/pensadores-textos-e-vídeos/fuganti-luiz/agenciamento. Acesso em 02.08.2013.

Geikie A. 1962. Founders of Geology. 2 ed. New York: Dover Publ. 486p.

Hallam A. 1989. Great geological controversies. 2 ed. Essex: Oxford Science Publ. 244p.

Le Goff J. 1990. O maravilhoso e o quotidiano no ocidente medieval. Lisboa: Ed. 70. p.14-235.

Monteiro G.M.V. 2007. Controvérsias geológicas: seu valor científico-histórico e didático. Aveiro: Depto. Didática Tecnologia Educativa. 456p. (Tese Dout.)

Régis de Morais J.F.1978. Filosofia da ciência e da tecnologia: introdução metodológica e crítica. 5 ed.

Potapova M.S. 2008. Geologia como uma ciência histórica da natureza. Terrae Didatica, 3(1):86-90. [Trad. de: Potapova M.S 1968. Geology as an historical science of nature. In: Interaction of the science in the study of the Earth. Moscow: Progress, p.117-126]. URL: http://www.ige.unicamp.br/ terraedidatica/v3/v3_a7.html. Acesso 27.02.2014.

Randles W.G.L. 1994. Da terra plana ao globo terrestre: uma mutação epistemológica rápida (1480-1520) Trad. Maria Carolina F. C. Pires. Campinas: Papirus. $162 \mathrm{p}$.

Rudwick M.J.S. 1987. El Significado de los Fóssiles. Trad. Antonio Resines. Madrid: Herman Blume. 347 p.

Sousa Santos B. 2003. Um discurso sobre as ciências. São Paulo, Cortez. 58p.

Stengers I. 2002. A invenção das ciências modernas. Trad. Max Altman. São Paulo: Ed. 34. 208p.

Trindade D.F., Trindade L.S.P. 2007. Os caminhos da ciência e os caminhos da educação: ciência, história e educação na sala de aula. São Paulo: Madras. 254p. 